\title{
Underground Transport: An Overview
}

\author{
Jianqiang Cui ${ }^{* *}$ and John D Nelson ${ }^{2}$ \\ 1. School of Environment and Science, Griffith University, Brisbane, Australia \\ 2. Centre for Transport Research, School of Engineering, University of Aberdeen, Aberdeen, United Kingdom
}

\begin{abstract}
Transport systems play an essential role in urban, economic and social development. Utilising underground space for transport is a continuing trend across the globe during past decades. Underground transport systems have been chosen by cities as potential solutions for solving urbanisation problems such as traffic congestion, land shortage, and noise and air pollution. This paper provides an overview of five main forms of underground transport: underground railway systems, underground car parks, urban underground roads and expressways, underground freight transport systems and underground pedestrian systems. In each case the overview explores their origins, development, advantages and challenges, as well as other research foci. The paper then discusses key policy challenges for underground transport systems and provides recommendations for future research.
\end{abstract}

Keywords: Transport systems; Underground transport; Underground space

\section{Introduction}

It is anticipated that by $205066 \%$ of the world's population will be urban dwellers. This continued urbanisation generates pressures for the greater use of urban space. Previous research has shown that urban underground space (UUS) utilisation can contribute to sustainable urban development (Sterling and Nelson, 2013), city resiliency (Sterling et al., 2012) and the building of livable cities (Hunt et al., 2016). Underground development is considered to be a vital tool in reshaping cities to cope with the challenges of the future (Broere, 2016).

Transport systems provide one of the key infrastructure services to urban society (D'Lima and Medda, 2015). Utilising underground space for transport and other purposes is a continuing trend in urban development over the past decades (Zhao and Künzli, 2016). Transport is viewed as an important function of UUS for addressing complex transport problems in cities (Cui et al., 2013a, b; Sterling, 1997). Underground transport systems have been chosen by cities as potential solutions for solving problems of traffic congestion, noise and air pollution, and issues associated with high density urbanisation (ITA Working Group on Costs-benefits of Underground Urban Public Transportation, 1987).

Darroch et al (2016) note that calls for the use of UUS under buildings or highways, not just for foundations but as additional functional space, are well established (e.g. Bobylev, 2009; Cui et al., 2013b) and that in the case of the railways relevant experience dates back to the nineteenth century. The world's oldest urban underground metro line, London's Metropolitan Railway from Paddington to Farringdon, opened in 1863, while underground parking systems have become widespread since their appearance in the 1920s. The first underground freight transport system was in operation in 1853 in London, and underground pedestrian systems (such as the PATH system in Toronto) have been actively developed since the early 1900s. In the current motorised society, underground roads and expressways have been built in large cities to reduce the negative environmental impacts caused by (surface) traffic and to enhance the entire transport network.

Darroch et al. (2018) note that UUS generally requires physical structures, referred to as Urban Underground Infrastructure (UUI), to create the necessary space (e.g. tunnels; floors; ceilings; girders; walls; shafts). They observe that these structures interact with the subsoil and other urban infrastructure (buildings; basement levels; other tunnels; transport infrastructure; utilities) and that these structures and the adjacent land can be owned by 
or be the responsibility of different parties (although not all parties may be aware of this). As such, good governance in the planning, design, construction, management, operation of underground transport systems is essential to ensure the sustainability of urban environments as well as the UUS itself.

This paper is structured as follows. Following the introduction to the key concepts of UUS, UUS for underground transport and UUI, the paper provides an overview of five main forms of underground transport: underground railway systems, underground car parks, urban underground roads and expressways, underground freight transport systems and underground pedestrian systems. In each case the overview explores their origins, development, advantages and challenges, as well as other research foci. The paper then discusses key policy challenges for underground transport systems and provides recommendations for future research.

\section{Underground railway systems}

An urban underground railway is typically defined as one which runs within the built-up limits of a city, giving good penetration of the city centre by tunnels. White (2016) notes that underground rail networks are largely self-contained and that often over half of the network may be sited on the surface or on elevated track. Ownership commonly rests with a city transport authority and in many European cities responsibility extends to include the planning and operation of light rail and bus services.

During the nineteenth century railways served almost all demands for mechanized transport (White, 2016). The London Underground, constructed largely between 1890 and 1955 (following commencement of the Metropolitan line in 1863), is a prime example of a specialised urban railway. The Paris metro was inaugurated in 1890 and by 1940 there were seventeen metros in operation (including Hamburg, New York, Chicago and Moscow). To-day heaviest use of metros is experienced in large cities in South America and Asia. For example, every work day more than 10 million passengers take Shanghai's subway system, the largest metro system in the world by route length, with a current network of 644 kilometres.

The relationship between underground rail and economic development has been widely examined in the literature. Levinson et al. (2016) note that the high ridership of London's Metropolitan Railway quickly spawned interest in the construction of additional links. In their exploration of the role accessibility played in the decision to approve or reject proposed early London Tube schemes they find that maximizing accessibility to population per expenditure largely explains Parliamentary approvals and rejections. Transport for London (2017) note that there is a vast theoretical and empirical literature that supports the idea that the benefits of transport schemes get capitalised into higher land values and cite the existence of a 'transport premium' of up to $10.5 \%$ around Tube and rail stations in London.

An important contemporary concern is the resilience of metro systems so that measures can be introduced to reduce the level of disruption when it occurs. D'Lima and Medda (2015) argue that it is important to be able to quantifiably measure the resilience of transport systems, and thus be able to make decisions on how the resilience of the system can be improved. Using the London Underground as an example they propose a measure of resilience by providing a quantification of the rapidity of the system's recovery from shocks which result in severe delays.

As with other forms of underground transport system the effects of metro systems on passengers' health is also an on-going concern. Wang et al. (2016) note that the Shanghai subway system's air quality has caused widespread concern because of the potential harm to passengers' health. Their study showed that particulate matter (PM) concentrations were higher on the platforms than inside the train and that PM concentrations on the platforms were influenced by the "piston wind" effect created by the approaching trains. Also, the effect of the piston wind varied among locations on the platform and was stronger at both ends of the platform than in the middle. Much can be done through the installation of appropriate ventilation systems both in tunnels and trains. A study in London showed that the concentrations of tunnel dust on the London Underground are unlikely 
to represent a significant cumulative risk to the health of workers or commuters, although efforts to reduce dust concentrations should continue, since the dust is not without toxicity (Seaton et al., 2005).

Digital technologies are being deployed to increase safety for trains and more efficient signaling and improved network performance. Increasing automation and the use of autonomous trains also offer prospects for improved reliability and efficiency of both passenger and freight movement. The Digital Railway Strategy in the United Kingdom draws inspiration from the progress made by London Underground and is predicated on establishing a "Digital as the Norm" culture in railway operations.

\section{Underground car parks}

Ison and Mulley (2014) provide an introduction to parking issues and policies, noting that since parking is primarily a land-use issue the management of parking is important when addressing the wider policy goals of impacting on traffic congestion, tackling the issue of air pollution, stimulating economic activity or aiming to improve road safety.

Just as in the case of underground railways the use of UUS for underground parking has been promoted as one solution to parking provision. The first underground city car park is thought to have been constructed in Pittsburgh in the 1920s (Cornwell, 2009). Some London hotels and apartment blocks constructed in the 1930s had car parks in their basements. The possible advantages of underground parking have been variously posited as including: easier access control, a secure environment, no obstruction of views or sunlight and improved liquid and solid waste pollution control (Gautam, 2018). Additionally, the possibility of freeing up land for nonparking use is an important land-use issue. On the downside the higher building, operational and maintenance costs cannot be ignored.

Estimating the capital cost of underground car parking projects is investigated in detail by Bastos et al. (2005) who review techniques for capital cost estimation. They draw on experience from Portugal where there has been a large programme of underground parking projects in the major cities and present a mathematical model for estimating capital costs of underground car parking projects, which in addition to the construction of the parking facility require complex ventilation, drainage, and fire safety systems. As in the case of underground railways the deviation of existing major underground urban services may be required during construction, thus requiring an effective means of determining the interfaces between the different types of urban infrastructure (Darroch et al., 2018).

Maintaining air quality in underground car parks is of particular importance since the concentration of exhaust emissions in enclosed environments can cause severe health impacts if appropriate ventilation is not maintained (see Viegas, 2010 for an investigation of ventilation issues in underground car parks). Yan et al. (2017) note that in large enclosed parking facilities, vehicle-induced air pollutants such as carbon monoxide (CO), PM10, and volatile organic compounds (VOCs) often occur at higher levels than in other indoor environments since vehicle emissions are higher during start-up and at lower speeds. These factors can be compounded by lack of adequate ventilation.

Demir (2015) reports the findings of a study which compared emission measurements in four underground and five aboveground multi-storey car parks in Istanbul when the density of motor vehicles was highest. Whilst no short-term risks to human health were identified they offer suggestions for improvements in design including: automated payment to encourage non-stop access to car parks; automated control of ventilation systems which are sensitive to emission concentrations and careful attention to the ventilation of working areas of employees. The effect of exposure to hazardous air pollutants for employees and users in six underground car parks in Guangzhou, China was investigated by Yan et al. (2017) where an obvious seasonal variation was noted. They conclude that more attention should be paid to the exposure of staff and users to hazardous air pollutants in underground car parks since definite risks to health were identified. 
Fires in car parks are fortunately quite rare but there are concerns regarding new and emerging risks from modern cars (which have increased electrical power and greater use of plastics) and alternative fuels (such as liquefied petroleum gas (LPG) and in the future, hydrogen). In the United Kingdom the basis for the existing Building Regulations guidance in for fire safety strategies in car parks relates to fire initiation and fire growth, although it is noted that they are based on research involving cars whose design is decades old. This is an area for further investigation.

\section{Urban underground roads and expressways}

A typical urban underground road/expressway travels through deep tunnels below a city, entering and exiting from portals that are integrated into the road networks (National Research Council of the National Academies, 2013). A recent study by Ma and Peng (2018) summarised the functions of underground roads in reducing traffic on the ground and improving the road network, freeing land for redevelopment, providing landscape conservation opportunities, reducing greenhouse gas emissions, and lowering accident rates in bad weather conditions. Hence, building underground roads and expressways in cities contributes to sustainable urban transport development. Many major cities across the globe have developed significant underground expressways, such as the A86 west tunnels in Paris (France), the M30 tunnels in Madrid (Spain), the Central Artery/Tunnel in Boston (United States), the Cross City Tunnel in Sydney (Australia), the Airport Link Tunnel and Clem Jones Tunnel in Brisbane (Australia), the Yamate Tunnel in Tokyo (Japan), and the Bund Tunnel in Shanghai (China).

The application of cost-benefit analysis has become one of the key topics in research on underground projects including underground roads and expressways. Usually, underground space development is perceived to be associated with high costs of underground construction, potential geotechnical risks and archaeological risks (Bobylev, 2009). The fiscal drawbacks may mitigate against the selection of underground space development from among other alternatives on the basis of financial feasibility. However, the high cost of underground development could be partially recovered by reduced cost for land purchase (Monnikhof et al., 1999). In addition, the social and environmental benefits of underground roads and expressways (such as reduced traffic congestion, noise and air pollution, land redevelopment and urban renewal) are barely considered in cost-benefit analysis. The National Research Council of the National Academies (2013) has indicated that it is not easy to quantify environmental and social impacts monetarily, and existing knowledge about these impacts of underground space use is limited due to lack of attention. Future research to evaluate the cost benefit of the entire lifecycle of underground road and expressway projects and to provide empirical evidence is needed.

How to address internal environment and safety issues has been an important focus in research on underground roads and expressways. Safe driving in underground roads is affected by psychological, visual and psychophysiological factors. As lighting is closely related to driving problems caused by these factors, accurate lighting installations can facilitate safe driving in underground roads (Peña-García, 2018). Fire safety is another key issue for tunnel projects. The increasing number of underground tunnels (and potentially the growing number of fire incidents) has forced authorities to reconsider more effective measures to reduce fire incidents in underground tunnels ( $\mathrm{Li}$ and Ingason, 2018). In addition to fire safety, the increasing number of underground tunnels has raised new questions concerning vehicular emissions and their impacts on human health due to enclosed tunnel environments. Further research is needed to identify the chemicals in tunnels and their concentrations, and to develop appropriate models of the tunnel portal emissions to aid in better design of the ventilation of future tunnels to decrease their environmental and health impacts (Kuykendall, 2009).

\section{Underground freight transport systems}

Urban freight transport is an increasing proportion of the urban transport task and is essential to the functioning of cities (Cui et al., 2015). Underground freight transport systems (also called underground logistics systems) 
are an important component of urban freight transport systems. Underground freight transport can take place in two forms: by vehicles or trains through underground tunnels; or by freight capsules through underground pipelines. The first underground freight transport system (pipeline) was introduced in 1853 for moving telegrams and postal mail from the centre to other offices in London (Zhao et al., 2018). Later, the system was exported to the rest of Europe, with similar installations following in Berlin (1865), Paris (1866) and Prague (1889) before it is spread to the rest of the world (Egbunike and Potter, 2011). The tunnel form of underground freight transport systems were introduced at the beginning of the twentieth century when rail-based underground freight transport systems were first developed in Chicago for transporting waste and coal (Visser and Geerlings, 2001).

Studies on the feasibility of modern underground freight transport have been conducted in various countries such as Germany, The Netherlands, United States and China. Researchers from Ruhr-University Bochum in Germany conducted a study on the feasibility of the CargoCap system, a freight pipeline system based on individually driven, computer-controlled transport units (Caps) (Stein and Schoesser, 2003). The Interdepartementale Projectorganisatie Ondergronds Transport (IPOT, Interdepartmental Project-team on Underground Transport), an interdepartmental underground transport task force comprising representatives from several Dutch ministries, examined the feasibility of underground freight transport (automated vehicles carrying cargo through tunnels) in the Netherlands (Wiegmans et al., 2010; Pielage, 2001). In the United States, the feasibility of using different technologies (such as the modern pneumatic capsule pipeline (PCP) technology) for underground freight transport in New York City was assessed by Liu (2004). The feasibility of a short-haul underground freight transport system (pipeline) to be applied to a large airport, Dallas-Fort Worth (DFW) International Airport, was investigated by Shahooei et al. (2018). Most recently, a metro-integrated logistics system that takes advantage of the existing passenger subway system for freight transport was proposed in Shanghai, China (Zhao et al., 2018).

Research has demonstrated the advantages and challenges of the implementation of underground freight transport. The possibility of a reduction in a city's reliance on trucks, and alleviation of congestion on roads and traffic, and environment-related problems such as air pollution and noise, was indicated by Liu (2004). For freight in pipelines, characteristics such as unhindered movement in a sealed dedicated transport system, potential for 24-hour operation daily, and electronic and computerised controls allow improved reliability and efficiency, and enable freight movement to be well-managed (Egbunike and Potter, 2011). However, there are planning, technological and political challenges for the implementation of underground freight transport. Visser (2018) highlighted the increasing difficulty of finding alignments for tunnels or tubes. For example, the appropriate UUS may have already been used up by underground facilities or shallow underground utilities in cities; this can be the case in China, European countries and the United States. In addition to the challenges around whether or not the technology of freight pipelines is acceptable as a feasible alternative to conventional freight transport systems (such as road transport), Egbunike and Potter (2011) also demonstrated that the absence of policy makers' interest has constrained the implementation of underground freight transport.

\section{Underground pedestrian systems}

According to Robertson (1993), an underground concourse linked with shopping complexes and/or underground transit can be viewed as an underground pedestrian system. A comprehensive definition of a well-developed underground pedestrian system is provided by Belanger's (2007) research based on Toronto's underground pedestrian system which contains a number of components: first, a retail complex with many shops; second, a small city linking various buildings and spaces such as office buildings, department stores and underground parking garages; and third, a transport infrastructure integrating different transport networks, such as subway and national / regional transit networks. The initial development of underground pedestrian systems can be found in Canadian cities. The early development of Toronto's underground pedestrian system can be traced back to 1917 when five underground tunnels connected the Eaton Centre main store, catalogue store, bargain annex and stable. However, it was not until the 1950s that the first planned network was officially proposed in 
Toronto (Belanger 2007). At present, Toronto's PATH underground pedestrian system in the city centre links restaurants, shops, entertainment and services along its $30 \mathrm{~km}$ underground route. In Montreal, the RESO underground pedestrian system's $32 \mathrm{~km}$ of tunnels cover more than 41 city blocks (Besner, 2007). Cities in East Asia and Europe, such as Tokyo, Osaka, Shanghai and Munich, also have numerous well-developed underground pedestrian systems.

The motivations behind the development of underground pedestrian systems have been explored in the literature. The development of underground pedestrian systems was believed to be initially driven by the need to provide shelter from poor weather conditions, such as in Toronto and Montreal with long and cold winters (Belanger, 2007). For Central Business Districts (CBD) with high density development (e.g. in Chicago), underground pedestrian systems were developed to alleviate congestion and pedestrian-vehicle conflicts (Bhalla and Pant, 1985). The economic potential of underground pedestrian systems in creating a second layer of downtown retailing has been recognised by planners and developers since the 1980s (Robertson, 1993). Private investment in the development of underground pedestrian systems with little or minimal public financial support was preferable for local government (Boisvert, 2007; Dillon, 1985). More recently, the development of underground pedestrian systems is also related to sustainable urban development (Durmisevic, 1999; Ronka et al., 1998; Sterling et al., 2012). However, fire and explosion were significant issues that directly affected the real safety of users in underground pedestrian systems (Forusz, 1980) because of the nature of the enclosed environment of such systems. As a result, fire and explosion disasters have hampered their development over time. Studies on safe evacuation of people and their rescue from complex underground pedestrian systems in an emergency need to be conducted in the future.

Current studies debate intensively the positive and negative impacts on the city and its people that the development of underground pedestrian systems may bring. Some studies praised the impacts of underground pedestrian systems in supporting transport and economy in city centres, while others questioned the ability of underground pedestrian systems to stimulate the long-term vitality of city centres (Maitland, 1992; Cui et al., 2013a). It is argued that the impacts of underground pedestrian systems on city vitality vary in different city contexts (Dillon, 1985; Terranova, 2009). For example, an underground pedestrian system would be advantageous in a dense urban development pattern.

\section{Key policy challenges for underground transport systems and directions for research}

This paper has provided an overview of five main forms of underground transport noting their origins, development, advantages and challenges. Each - underground railway systems, underground car parks, urban underground roads and expressways, underground freight transport systems and underground pedestrian systems - are firmly established as key components of the urban landscape.

The paper has highlighted the usefulness of UUS as a means to create additional functional space. Well-managed UUS is itself an effective means of increasing the density of urban environments globally. However, the need for good governance in the planning, design, construction, management and operation of underground transport systems is essential to ensure the sustainability of urban environments as well as the UUS itself.

Despite their many positive contributions to addressing the problems of surface transport systems such as traffic congestion, noise and air pollution it must be acknowledged that underground transport systems (once constructed) bring their own sets of challenges; e.g. with respect to safety (such as related to fires in road tunnels or underground car parks, personal security issues when travelling at night by underground railway or emergency evacuation from complex underground pedestrian systems); health (such as the effects of metro systems on passengers' health due to air quality or the effects of emissions on car users in road tunnels); and wider environmental externalities such as vibration from underground railway systems.

There are a number of important contemporary issues that policy makers must address, including the resilience of (for example) metro systems to terrorist threats or the impact of localised flooding on UUI. The contribution 
of underground roads and expressways in cities to sustainable urban transport development remains contested since the benefits of freed-up urban space (e.g. for land redevelopment, landscape conservation etc.), on the surface is counterbalanced by the high costs of underground construction. As noted earlier the fiscal drawbacks may mitigate against the selection of underground space development from among other alternatives on the basis of financial feasibility, although there is strong evidence that underground railways can contribute to land value uplift. However, it is not easy to quantify environmental and social impacts of underground transport systems monetarily so research to evaluate the cost benefit of the entire lifecycle of underground transport projects is needed. In the case of underground pedestrian systems some studies have praised their contribution towards supporting the economy in city centres, while others have questioned the ability of underground pedestrian systems to stimulate the long-term vitality of city centres, although the economic potential of underground pedestrian systems in creating a second layer of downtown retailing has long been recognised.

There are interesting prospects ahead for underground transport systems. Modern high-speed capsule freight transport systems using linear induction motors to power the capsules have been promoted for decades (e.g. Liu, 2000) and remain a strong possibility. Indeed, it has been argued that the absence of policy makers' interest has constrained the implementation of underground freight transport systems (Egbunike and Potter, 2011). Similarly, the increasing use of autonomous trains also offer prospects for improved reliability and efficiency of both passenger and freight movement. In addition, underground high-speed trains, as an emerging form of underground transport system, continues to attract increasing attention across the globe. In the United Kingdom and China, both researchers and practitioners are focusing on the issues with regard to its planning and engineering technology. This is also an area for future investigation.

\section{References}

Bastos, MF, Ribeiro, FL \& Teixeira, JC 2005, 'Estimating of capital cost of underground car parking project', Journal of Financial Management of Property and Construction, vol. 10, no. 2, pp. 126-132.

Belanger, P 2007, 'Underground landscape: the urbanism and infrastructure of Toronto's downtown pedestrian network', Tunnelling and Underground Space Technology, vol. 22, no. 3, pp. 272-292.

Besner, J 2007, 'Develop the underground space with a master plan or incentives', paper presented at the 11th ACUUS Conference, Athens, September 10-13.

Bhalla, MK \& Pant, PD 1985, 'Pedestrian traffic on Cincinnati skywalk system', Journal of Transportation Engineering, vol. 111, no. 2, pp. 95-104.

Bobylev, N 2009, 'Mainstreaming sustainable development into a city's master plan: A case of urban underground space use', Land Use Policy, vol. 26, no. 4, pp. 1128-1137.

Boisvert, M 2007, 'Extensions of indoor walkways into the public domain - a partnership experiment', paper presented at the 11th ACUUS Conference, Athens, September, 10-13.

Broere, W 2016, 'Urban underground space: Solving the problems of today's cities', Tunnelling and Underground Space Technology, vol. 55, pp. 245-248.

Cornwell, R 2009, 'The car park: A celebration of its place in history'. The Independent, 27 December 2009. Retrieved from: https://www.independent.co.uk/voices/commentators/rupert-cornwell/rupert-cornwell-the-carpark-a-celebration-of-its-place-in-history-1850869.html (accessed on 13/12/2018).

Cui, J, Allan, A \& Lin, D 2013a, 'The development of grade separation pedestrian system: A review', Tunnelling and Underground Space Technology, vol. 38, pp. 151-160. 
Cui, J, Allan, A, Taylor, MAP \& Lin, D 2013b, 'Underground pedestrian systems development in cities: Influencing factors and implications', Tunnelling and Underground Space Technology, vol. 35, pp. 152-160.

Cui, J, Dodson, J \& Hall, PV 2015, 'Planning for urban freight transport: An overview', Transport Reviews, vol. 35 , no. 5 , pp. 583-598.

Darroch, N, Beecroft, M \& Nelson, JD 2016, 'A conceptual framework for land use and metro infrastructure', Proceedings of the ICE - Infrastructure Asset Management, vol. 3, no. 4, pp. 122-131.

Darroch, N, Beecroft, M \&Nelson, JD 2018, 'Going underground: an exploration of the interfaces between underground urban transport infrastructure and its environment', Tunnelling and Underground Space Technology, vol. 81, pp. 450-462.

Demir, A 2015, 'Investigation of air quality in the underground and above ground multi-storey car parks in terms of exhaust emissions', Procedia - Social and Behavioral Sciences, vol. 195, pp. 2601-2611.

Dillon, D 1985, 'Dallas: a case study in skyway economics', Design Quarterly, no. 129, pp. 25-28.

D'Lima, M \& Medda, F 2015, 'A new measure of resilience: An application to the London Underground', Transportation Research Part A: Policy and Practice, vol. 81, pp. 35-46.

Durmisevic, S 1999, 'The future of the underground space', Cities, vol. 16, no. 4, pp. 233-245.

Egbunike, ON \& Potter, AT 2011, 'Are freight pipelines a pipe dream? A critical review of the UK and European perspective', Journal of Transport Geography, vol. 19, no. 4, pp. 499-508.

Forusz, HN 1980, The Cincinnati skywalk, Cincinnati, Ohio: A case study from the viewpoint of users and public authorities, University of Cincinnati Press, Cincinnati.

Gautam, S 2018, 'Underground parking: The solution to parking woes? Parking network. Retrieved from: http://www.parking-net.com/parking-industry-blog/get-my-parking/underground-parking-woes (accessed on $13 / 12 / 2018)$.

Hunt, DVL, Makana, LO, Jefferson, I \& Rogers, CDF 2016, 'Liveable cities and urban underground space', Tunnelling and Underground Space Technology, vol. 55, pp. 8-20.

Ison, SG \& Mulley, C 2014, Introduction. In Ison, S \& Mulley, C (ed.) Parking: Issues and policies, Emerald Group Publishing Limited, pp. 1-9.

ITA Working Group on Costs-benefits of Underground Urban public Transportation 1987, 'Examples of benefits of underground urban public transportation systems', Tunnelling and Underground Space Technology, vol. 2, no. 1 , pp. 5-54.

Kuykendall, JR, Shaw, SL, Paustenbach, D, Fehling, K, Kacew, S \& Kabay, V 2009, 'Chemicals present in automobile traffic tunnels and the possible community health hazards: A review of the literature', Inhalation Toxicology, vol. 21, no. 9, pp. 747-792.

Levinson, DM, Giacomin, D, \& Badsey-Ellis, A 2016, 'Accessibility and the choice of network investments in the London Underground', Journal of Transport and Land Use, vol. 9, no. 1, pp. 131-150.

Li, YZ \& Ingason, H 2018, 'Overview of research on fire safety in underground road and railway tunnels', Tunnelling and Underground Space Technology, vol. 81, pp. 568-589.

Liu, H 2000, 'Pneumatic capsule pipeline - Basic concept, practical considerations, and current research', Proc. Mid-Continent Transportation Symposium 2000 Proceedings, pp. 230-234. 
Liu, H 2004, Feasibility of underground pneumatic freight transport in New York City, Freight Pipeline Company, Columbia, Missouri.

Ma, C-X \& Peng, F-L 2018, 'Some aspects on the planning of complex underground roads for motor vehicles in Chinese cities', Tunnelling and Underground Space Technology, vol. 82, pp. 592-612.

Maitland, B 1992, 'Hidden cities - the irresistible rise of the North American interior city', Cities, vol. 9, no. 3, pp. 162-169.

Monnikhof, RAH, Edelenbos, J, van der Hoeven, F \& van der Krogt, RAA 1999, 'The new underground planning map of the Netherlands: a feasibility study of the possibilities of the use of underground space', Tunnelling and Underground Space Technology, vol. 14, no. 3, pp. 341-347.

National Research Council of the National Academies 2013, Underground engineering for sustainable urban development, The National Academic Press, Washington, DC.

Peña-García, A 2018, 'The impact of lighting on drivers well-being and safety in very long underground roads: New challenges for new infrastructures', Tunnelling and Underground Space Technology, vol. 80, pp. 38-43.

Pielage, BJ 2001, 'Underground freight transportation. A new development for automated freight transportation systems in the Netherlands', IEEE Intelligent Transportation Systems Conference, Oakland, CA, USA, Aug. 2529.

Robertson, KA 1993, 'Pedestrians and the American downtown', Town Planning Review, vol. 64, no. 3, pp. 273-286.

Ronka, K, Ritola, J \& Rauhala, K 1998, 'Underground space in land-use planning', Tunnelling and Underground Space Technology, vol. 13, no.1, pp. 39-49.

Seaton, A, Cherrie, J, Dennekamp, M, Donaldson, K, Hurley, JF \& Tran, CL 2005, 'The London Underground: dust and hazards to health', Occupational and Environmental Medicine, vol. 62, no.6, pp. 355-362.

Shahooei, S, Farooghi, F, Zahedzahedani, SE, Shahandashti, M \& Ardekani, S 2018, 'Application of underground short-haul freight pipelines to large airports', Journal of Air Transport Management, vol. 71, pp. 64-72.

Stein, D \& Schoesser, B 2003. CargoCap-transportation of goods through underground pipelines: Research project in Germany, Pipeline Engineering and Construction International Conference, Baltimore, Maryland, United States.

Sterling, R 1997, 'Underground technologies for livable cities', Tunnelling and Underground Space Technology, vol. 12 , no. 4 , pp. $479-490$.

Sterling, R, Admiraal, H, Bobylev, N, Parker, H, Godard, J-P, Vähäaho, I, Rogers, CDF, Shi, X \& Hanamura, T 2012, 'Sustainability issues for underground space in urban areas', Proceedings of the Institution of Civil Engineers - Urban Design and Planning, vol. 165, no. 4, pp. 241-254.

Sterling, R \& Nelson, P 2013, 'City resiliency and underground space use', in Zhou, Y, Cai, J \& Sterling, R (Eds.), Advances in Underground Space Development, Research Publishing, Singapore, pp. 43-55.

Terranova, CN 2009, 'Ultramodern underground Dallas: Vincent Ponte's pedestrian-way as systematic solution to the declining downtown', Urban History Review, vol. 37, no. 2, pp. 18-29. 
Transport for London 2017, 'Land value capture'. Final Report of a joint study by Transport for London and the Greater London https://www.london.gov.uk/sites/default/files/land_value_capture_report_transport_for_london.pdf Authority.

Viegas, JC 2010, 'The use of impulse ventilation for smoke control in underground car parks', Tunnelling and Underground Space Technology, vol. 25, pp. 42-53.

Visser, JGSN 2018, 'The development of underground freight transport: An overview', Tunnelling and Underground Space Technology, vol. 80, pp. 123-127.

Visser, JGSN \& Geerlings, H 2001, 'Technological innovations in transport: An implementation strategy for underground freight transport', in: Feitelson, E \& Verhoef, ET (Eds.), Transport and Environment: In Search of Sustainable Solutions. Edward Elgar Publishing, Cheltenham, UK, pp. 136-156.

Wang, J, Zhao, L, Zhu, D, Gao, H O, Xie, Y, Li, H, Xu, X \& Wang, H 2016, 'Characteristics of particulate matter (PM) concentrations influenced by piston wind and train door opening in the Shanghai subway system', Transportation Research Part D: Transport and Environment, vol. 47, pp. 77-88.

White, P 2016, Public transport: Its planning, management and operation. $6^{\text {th }}$ edition. London: Routledge.

Wiegmans, BW, Visser, J, Konings, R \& Pielage, B-JA 2010, 'Review of underground logistic systems in the Netherlands: An ex-post evaluation of barriers, enablers and spin-offs', European Transport / Trasporti Europei, no. 45 , pp. 34-49.

Yan, Y, He, Q, Song, Q, Guo, L, He, Q \& Wang, X 2017, 'Exposure to hazardous air pollutants in underground car parks in Guangzhou, China', Air Quality, Atmosphere \& Health, vol. 10, iss. 5, pp. 555-563.

Zhao, J \& Künzli, O 2016, 'An introduction to connectivity concept and an example of physical connectivity evaluation for underground space', Tunnelling and Underground Space Technology, vol. 55, pp. 205-213.

Zhao, L, Li, H, Li, M, Sun, Y, Hu, Q, Mao, S, Li, J \& Xue, J 2018, 'Location selection of intra-city distribution hubs in the metro-integrated logistics system', Tunnelling and Underground Space Technology, vol. 80, pp. 246256. 